\title{
The Production Management System Based on Digital Pulp Pipeline Design and Development
}

\author{
Liu Hongwei ${ }^{1, a}$, Xiao Ke ${ }^{2, b}$, Chunlei $\mathrm{Pan}^{3, \mathrm{c}}$ and Guangyue $\mathrm{Pu}^{4, \mathrm{~d}}$ \\ ${ }^{1}$ Yunnan Da Hongshan Pipeline Co., Ltd., Kunming, 650504, China \\ ${ }^{2}$ Faculty of Information Engineering and Automation, Kunming University of Science and \\ Technology, Kunming, 650500, China \\ a1162494119@qq.com, b530703461@qq.com \\ csteelkm@foxmail.com, ${ }^{\mathrm{d}} \mathrm{km}$ trans@foxmail.com
}

Keywords: Slurry pipeline; Management standards; Resource sharing; effectiveness

\begin{abstract}
In light of the present condition of the enterprise production management system and single management means, management is not standard, most people are involved in the production management, production management standard is not unified, the production management problems such as difficult maintenance. Based on slurry pipeline as the background, each department management confusion, lack of communication between departments, paper study design a set of integrated automation digital pipeline production management system, the system according to the actual production management needs to establish the management standard specification, implement the working process of motivation, the product producing the intellectualized management maintenance and resource sharing, etc. Practical application shows that the effectiveness and superiority of the scheme.
\end{abstract}

\section{Introduction}

Yunnan great pipe co., LTD was established on August 1, 2008, is a wholly owned subsidiary of Kun Ming iron and steel co., LTD., is specialized is engaged in the mineral pipeline and other solid material pipeline control technology research, development and management of technical research and development and service company. Burdened with will be a great iron concentrate is safe, reliable, efficient and economic through pipes to the important mission of Kun Ming steel, is an important lifeline of Kun Ming steel raw material conveying ore. A great long pipe line, pipe distribution in the rugged, total length of $171 \mathrm{~km}$, for the national transport length the first iron ore concentrate. It was set up along the five power stations, water, materials, and in the end to set up three dewatering stand separation. Da Hong Shan pipeline company over the past few years of development, has successively built the company's web site platform, control integration systems, data acquisition and monitoring of SCADA system, slurry characteristics data management system and production information such as video monitoring platform. But due to the Da Hong Shan pipeline management dispersed, management means such as single reason has not set up a reasonable and scientific management system.

With the rapid development of information technology, enterprise management system is increasingly perfect ${ }^{[1]}$, the Da Hong Shan pipeline management still exists some deficiencies: the management confusion between the various departments, the communication between the various departments is not enough, effect on production order; Spare part inventory cannot be timely understanding, which affect the head of the formulation and implementation of production plan ${ }^{[2]}$; Some large items machinery operation cannot be timely feedback to policy makers, cause not timely maintenance, there may be a mechanical failure, production risk, cause great economic losses to enterprises; Not Shared network, the information management department work coordination is not smooth, influence enterprise production benefit ${ }^{[2]}$. Comes along with the strength of the problems, a kind of digital management concept arises at the historic moment, so we put forward the solution of digital pipeline.

The digital pipeline is a support enterprise development strategic solution. It's in the "unified 
planning, step-by-step implementation, the key breakthrough" management concept, advocate and support the digital management of enterprise production, real-time monitoring of manufacturing and production data, dynamic analysis and decision is closely related to the enterprise lifeblood, make the enterprise can be in a safe and stable environment benign development better. This paper is a system solution based on digital pipeline. According to the standard of company material management ${ }^{[3]}$ and this system through the analysis of the key process and key management system, roles and characters, distribution department implements production line management, not only achieved the resources sharing of production management, also make each in charge of the department can better work together, and then make the production and management activities of benign orderly, improve enterprise economic benefits.

\section{System design scheme and structure of the module}

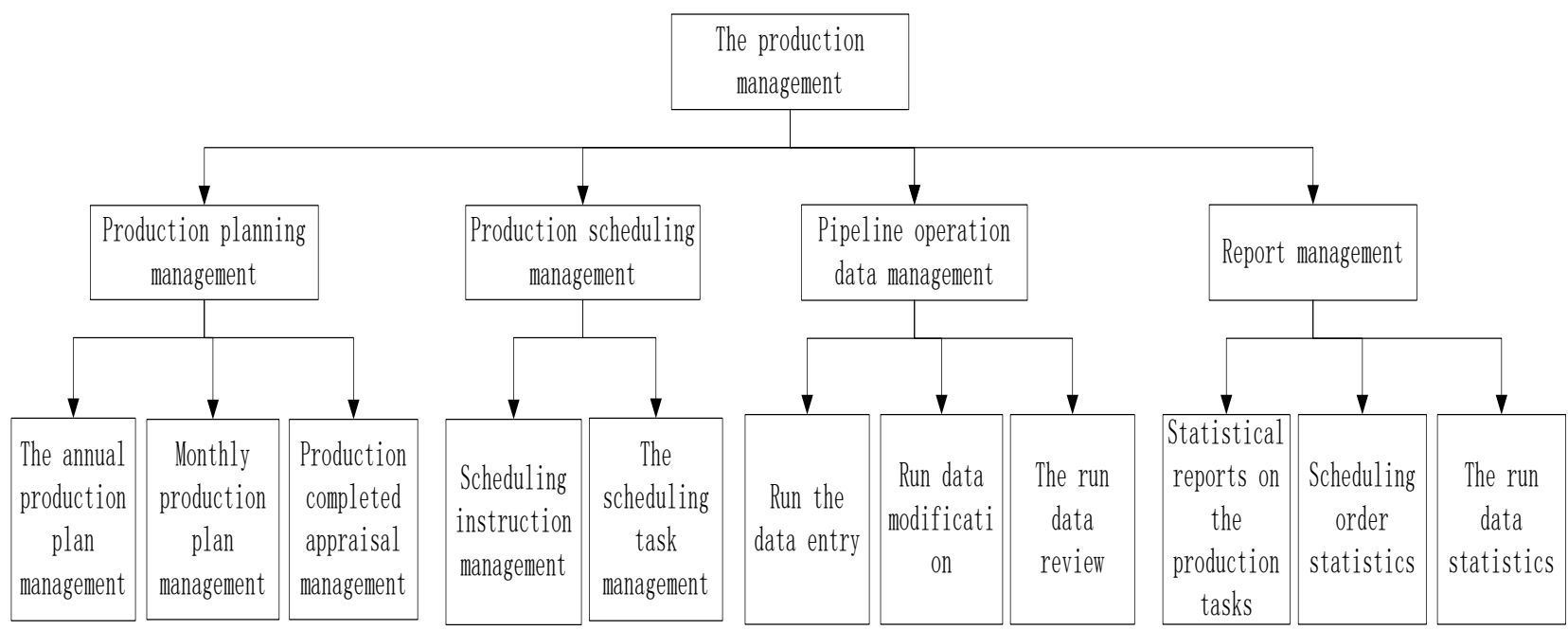

Figure1. The production management system function structure

(1) Production plan management: mainly deal with the formulation of annual and monthly production plan, report, audit and assessment for the production task completion.

(2) Production scheduling management: mainly to complete the dispatch instructions issued, CuiBan, tasks, task completion audit and score.

(3) Pipeline operation data management: used for equipment operation of online data acquisition, acquisition data change and audit after warehousing. Ore time of the pipeline, water time, size head tail arrival, etc.

(4) Report management: used to generate the production related reports, mainly includes: day, week, month and year plan the task completion statistics. Shift day, week, month and year task to complete statistics. Each shift scheduling command completion statistics. Each operator instruction completion statistics. Day, week, month and year pipeline operation data statistics.

\section{System work process analysis}

In order to do the production of fine operation, fine management, further excavate the existing equipment and personnel Potential value, it is necessary to make production from how to effectively control and other aspects. For the production controlling, mainly including production planning and production scheduling process. For a production plan to do: plan content can query, plan implementation can be controlled, the planning process traceability, planning results can be analyzed. For production scheduling command issued and executive control do: orders arrives station, task allocation to people, and execution trace, finish the statistics.

(1) Production plan management:

Mainly deal with the formulation of annual and monthly production plan, report, audit and assessment for the production task completion. 
(2)The production scheduling management:

Main scheduling command issued, CuiBan, task assignment, task completion audit and score.

(3) The pipeline operation data management:

Used for equipment operation of online data acquisition, acquisition data change and audit after warehousing. Ore time of the pipeline, water time, size head tail arrival, etc.

(4) Report management:

Used to generate the production related reports, mainly include:

- day, week, month and year plan task completion statistics.

- shift day, week, month and year task to complete statistics;

- each shift scheduling command completion statistics;

- each operator instruction completion statistics.

- day, week, month and year pipeline operation data statistics.

Production planning management. Production planning management is an important part of enterprise management. It is directly related to the success or failure of enterprise management and provided quality and quantity of the product to the society. With the globalization of economy, tariff barriers $^{[4]}$ in gradually eliminate, technical standard barriers in gradually formed, product export must meet the corresponding quality and management standards to a passport to enter the international market. All of these in some sense related to enterprise production planning management.

Production scheduling management. $\mathrm{Job}^{[4]}$ scheduling is a main part of enterprise management, reflect the self restriction, self supervision, self management role. Dispatching center is mine level leadership to organize the daily production headquarters, each production links, do well in the comprehensive balanced hub. Specification for scheduling management procedures, management functions of the dispatch room ${ }^{[5]}$, create a pragmatic, efficient, innovative style of work, to ensure the safety of the harmonious order of production.

Data management of pipeline operation. The pipeline to form a large amount of data in the long-term construction, operation, maintenance and management process, including the completion data, running records, inspection records, repair records, inspection record etc.. These data due to the formation of the times are different, therefore in the form, format, content and requirements there are certain differences and digital data. In order to achieve unified storage management, convenient use, must be consolidated and digital processing of these historical data.

Report management. Report management system is a comprehensive strong independent system, through the preparation of accounting statements, to make the general description of accounting unit. The relevant accounting information management system data from the financial system and other individual accounting system, is a complex and tightly with other accounting subsystem. Therefore, must be based on daily accounting work, in order to give full play to the role of report management system.

\section{Summary}

This paper discusses the technical scheme of the production management system application framework based on digital pipeline. This framework has been successfully used in the production management system of Da Hong Shan pipeline digital operation platform design and development practice, the application of the core module has been developed, the system is applied in Da Hong Shan pipeline company debugging. Practice shows that, this system shows the unique superiority, has the following main advantages: the system standard process provides to the related department to provide a convenient, reduce workload, improve work efficiency; the user can understand the system workflow progress in real-time, so that the command scheduling becomes do a job with skill and ease, enhance the coordination of various departments. 


\section{Acknowledgement}

This work is supported by National Natural Science Foundation of China (No. 51169007), Science \& Research Program of Yunnan province (No.2011CI017 \& 2012CA022\&2013DH034).

\section{Reference}

[1] WANG Rui-ping,TAN Zhi-qiang,et all. Technique Research and Development Summarization of “Digital Pipeline” [J]. Geomatics \& Spatial Information Technology,2011,34(1):1-9.

[2] R.Kh.Zaripov.A production system in music.[J].Sov.J.Comput.Syst. Sci.,1987,25(6).

[3] YIN Mao-cong. Economic and technical indicators Thermal Power Plant[J]. Management \& Technolosy of SME,2010,(3):4

[4] J-J Peters.The EBU's activities in production technology[J].EBU TECHNICAL REVIEW, 1997(272).

[5] ZHU Guozhong,WEI Caihong, PAN Min.The Research of Energy Expenditure Detection Algorithm Based on Tri-Axial Acceleration Transducer[J]. Chinese Journal Of Sensors And Actuators, 2011,24(8): 1217-1222. 